\title{
Estimating Sediment Mass Fluxes on Surfaces Sheltered by Live Vegetation
}

\author{
Benjamin Walter ${ }^{1,2}$. Christian Voegeli ${ }^{1}$. \\ Stefan Horender ${ }^{1}$
}

Received: 28 June 2016 / Accepted: 8 December 2016 / Published online: 26 December 2016

C) Springer Science+Business Media Dordrecht 2016

\begin{abstract}
We present a simple model based on already existing and widely used equations for estimating particle mass fluxes on surfaces sheltered by live vegetation. Wind-tunnel measurements of vertical profiles of mass flux in three different dense live plant canopies, and as a function of the spatially averaged skin friction velocity $u_{\tau}{ }^{\prime}$, provide the baseline set of data. For the bare-sand surface, the total mass flux $Q$ shows the typical $b\left(u_{\tau}{ }^{\prime}-u_{\tau t^{\prime}}\right)^{3}$ increase with increasing skin friction velocity $u_{\tau}{ }^{\prime}$, where $b$ is a constant and $u_{\tau t}{ }^{\prime}$ is the threshold at the onset of particle erosion. Similar relations, however, with different values for $b$ and $u_{\tau t}{ }^{\prime}$ compared to the bare-sand surface were found for experiments with 5.25 and 24.5 plants $\mathrm{m}^{-2}$ and can be explained by the spatial variations of $u_{\tau}$ for the canopy cases. Based on the resulting parameters $b$ and $u_{\tau t}{ }^{\prime}$, which are found to be functions of the roughness density $\lambda$, we present a final simple relation $Q\left(\lambda, u_{\tau}{ }^{\prime}\right)$ used for estimating the total mass flux for surfaces sheltered by live vegetation.
\end{abstract}

Keywords Particle entrainment - Sediment mass flux · Surface shear stress · Wind erosion · Wind tunnel

\section{Introduction}

The sheltering effect of vegetation against wind erosion results in reduced sediment mass fluxes over erodible surfaces. Modelling sediment mass fluxes for various boundary conditions, such as particle size, wind speed, or the degree to which a surface is sheltered by vegetation, still remains challenging in aeolian research. Various sophisticated models have been developed for the determination of particle mass fluxes for sheltered surfaces. These are

$凶$ Benjamin Walter

walter@slf.ch

1 WSL Institute for Snow and Avalanche Research SLF, Davos Dorf, Grisons, Switzerland

2 Physikalisch Meteorologisches Observatorium Davos and World Radiation Center (PMOD/WRC),

Dorfstrasse 33, 7260 Davos Dorf, Switzerland 
impractical for determining or even estimating mass-flux magnitudes (e.g. Shao and Li 1999; Nemoto and Nishimura 2004; Okin 2008; Li et al. 2013). Okin (2008) and Li et al. (2013) both presented erosion models for vegetated surfaces mainly based on Shao and Raupach (1993). Okin (2008) makes use of the size distribution of erodible gaps between plants to determine the average shear stress at the surface, whereas the formulation of Li et al. (2013) includes many parameters that result in a quite complex formulation. Some approaches use large-eddy simulation (LES) (e.g. Weil et al. 2004; Vinkovic et al. 2006; Diebold et al. 2013; Groot-Zwaaftink et al. 2013, 2014). However, many land-surface schemes and models used for climate change assessment (e.g. Thornton and Zimmermann 2007) need simple parametrizations of the particle mass fluxes.

Hesp (1981) and Bitton and Hesp (2013) experimentally investigated the influence of live vegetation on the formation of coastal dunes, whereas much attention has been paid to the investigation of the sheltering effect of non-erodible roughness elements, such as plants, by measuring the surface shear stress in wind-tunnel and field studies (e.g. Gillette and Stockton 1989; Crawley and Nickling 2003; Walter et al. 2012b). The dependence of the particle mass flux on the wind speed or friction velocity has been extensively investigated for bare, nonsheltered surfaces, e.g., by Bagnold (1941), Pomeroy and Gray (1990), Nishimura and Hunt (2000), McKenna Neuman (2003), Kok et al. (2012). However, to the best of our knowledge, previous wind-tunnel studies quantifying particle mass fluxes as a function of wind speed have only investigated bare sediment surfaces without vegetation or non-erodible roughness elements on the ground. On the other hand, wind-tunnel studies investigating the sheltering effect of non-erodible roughness elements have typically focused on varying canopy densities, neglecting the influence of wind speed on particle mass fluxes. Here, we present particle massflux measurements for canopies sheltered by live vegetation of different densities together with a simple quantitative relationship for the particle mass flux as a function of both the skin friction velocity $u_{\tau}{ }^{\prime}$ and the canopy density $\lambda$. Despite the fact that the results are based on a limited set of wind-tunnel measurements, the contribution presents a first estimate of the relevant parameters that can be used in larger-scale models.

A widely used and simple relation for calculating the particle mass flux $Q$ on bare sediment surfaces as a function of the friction velocity $u_{*}$ (of the constant-stress layer) is defined as (Bagnold 1941)

$$
Q\left(u_{*}\right)=b_{1}\left(u_{*}-u_{* t}\right)^{3},
$$

where $b_{1}$ is a proportionality factor and $u_{* t}$ is the threshold friction velocity defining the initiation of particle erosion. The dependence of the particle mass flux on the roughness density $\lambda$, defined as the roughness element frontal area $A_{\mathrm{f}}$ divided by the surface area $S$ per roughness element (Raupach 1992), has typically been investigated only for specific wind speeds (e.g. Burri et al. 2011). Note that the roughness density $\lambda$ used here does not account for the so-called Telephone Pole problem as discussed in Okin (2008). The dependence of the mass flux $Q$ on the roughness density $\lambda$ is often described by the following exponential function (Hesse and Simpson 2006; Li et al. 2007; Burri et al. 2011)

$$
Q(\lambda)=b_{2} \exp (c \lambda),
$$

where $b_{2}$ is the mass flux for the bare sediment surface $(\lambda=0)$ and $c$ is an empirical constant. Our goal is to simply provide a combination of Eqs. 1 and 2 to obtain a single relation for calculating particle mass fluxes on sheltered surfaces as a function of both the roughness density $\lambda$ and the skin friction velocity $u_{\tau}{ }^{\prime}$. The resulting function is expected to be of the form

$$
Q\left(\lambda, u_{\tau}^{\prime}\right)=b(\lambda)\left(u_{\tau}^{\prime}-u_{\tau t}{ }^{\prime}(\lambda)\right)^{3}
$$


where $b(\lambda)$ represents the exponential decrease of $Q$ with increasing roughness density $\lambda$ as described by Eq. 2. For the second term of Eq. 3 (see Eq. 1), the friction velocity $u_{*}$, which also defines the total shear stress $\tau=\rho u_{*}^{2}$ on the entire canopy, is replaced by the spatial average $u_{\tau}{ }^{\prime}$ of the skin friction velocity $u_{\tau}=\left(\tau_{s} / \rho\right)^{1 / 2}$. Here, $\rho$ is the air density and $\tau_{s}$ is the surface shear stress acting solely on the ground beneath the roughness elements (Raupach 1992). This replacement is justified when we consider that the drag acting directly on the underlying surface, rather than the total drag on the entire canopy, is responsible for the initiation of particle entrainment and the resulting magnitude of the particle mass flux. For a bare surface without roughness elements $(\lambda=0), u_{\tau}^{\prime}=u_{*}$.

The experimental methods and the applied measurement techniques are described in Sect. 2, and in Sect. 3 the results are presented and discussed, and the new model equations are introduced. Finally, Sect. 4 provides a summary, including an outlook.

\section{Methods}

The experiments were performed in the boundary-layer wind tunnel (e.g. Walter et al. 2012a) of the Institute for Snow and Avalanche Research (WSL/SLF); the wind tunnel (Fig. 1) has an 8-m-long test section and a cross-sectional area of $1 \mathrm{~m}^{2}$. Three live plant canopies of different roughness densities $\lambda=0,0.03$, and 0.13 (further named as bare surface, lowdensity, and high-density cases) were used (Fig. 1), with plants (ryegrass) grown in plastic tubes inside a climate chamber and cut to a standard height $h=100 \mathrm{~mm}$. Additional information on the plants, their size, and frontal area can be found in Walter et al. (2012b,c). For all experiments, a 10-mm-thick layer of sieved quartz sand of size distribution $d=0.4$ $0.8 \mathrm{~mm}$ was spread on the ground beneath the plant canopies. The grain-size distribution was $>0.8 \mathrm{~mm}(4 \%), 0.63-0.80 \mathrm{~mm}(54 \%), 0.40-0.63 \mathrm{~mm}(40 \%)$, and $<0.40 \mathrm{~mm}(2 \%)$. The sand was rather coarse compared to previous studies, but, for consistency, it was chosen to conform to that used in Burri et al. (2011). The mass-flux measurements are identical to those performed by Burri et al. (2011) in the WSL/SLF wind tunnel, but we used several wind speeds for each canopy density, whereas Burri et al. (2011) performed measurements at only a single wind speed. A segmented sand sampler for wind-tunnel studies (WITSEG, Dong et al. 2004; Burri et al. 2011) with 60 vertical bins on top of each other was used to measure the vertical mass-flux profiles $q(z)$ up to a height of $0.54 \mathrm{~m}$, where $q$ is the mass flux per bin of the sediment sampler. Each bin has a height of $9 \mathrm{~mm}$ and a width of $5 \mathrm{~mm}$, with the sampler mounted on the ground so that the opening of the lowest chamber was flush with the sand surface. The distance between the nearest plant upstream and the sediment sampler varied according to the canopy density (Burri et al. 2011). The plant-canopy measurements were performed at two different locations: one where the sampler was placed in line with the plant rows and one where the sampler was placed in between the rows (Fig. 1). The freestream velocity $U_{\delta}$ was measured with a fan anemometer at a height of $700 \mathrm{~mm}$ above the surface and ranged from $12-19 \mathrm{~m} \mathrm{~s}^{-1}$ depending on the experiment. For each canopy the lowest freestream velocity was chosen so that a measureable amount of sediment was eroded. From thereon the wind speed was increased in steps of $1 \mathrm{~m} \mathrm{~s}^{-1}$ until the mass flux was so high that the sand layer was already significantly eroded before the target wind speed was reached. The saltation layer had a maximum height of $0.5 \mathrm{~m}$ in all experiments and was thus always significantly lower than the wind-tunnel ceiling. The sediment sampler was covered with a shield as long as the wind speed increased towards the target wind speed. The experiments ceased when locations within the wind tunnel occurred where the entire 10-mm- 

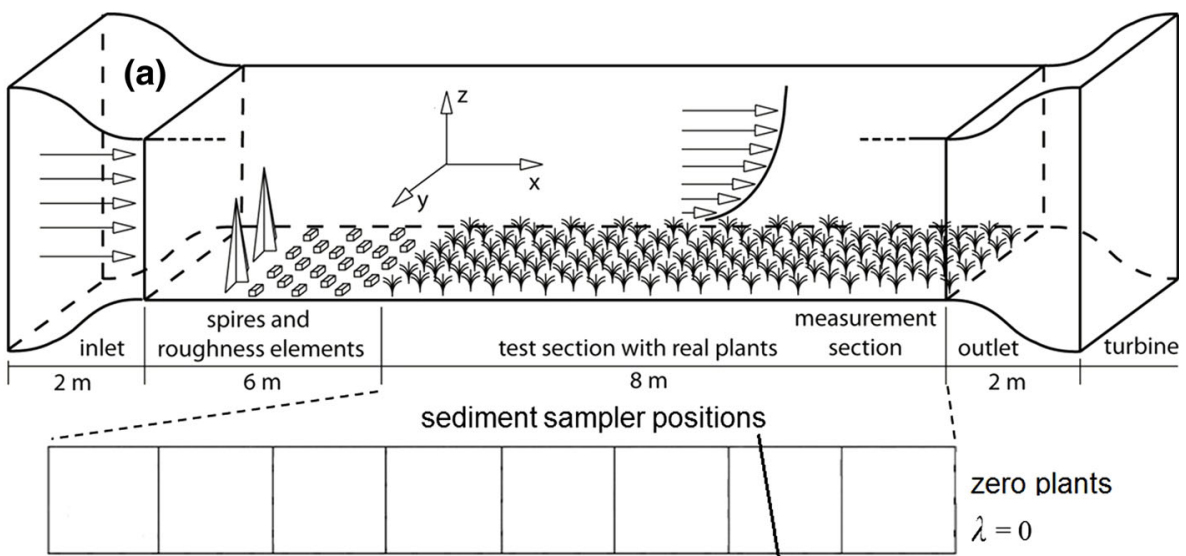

(b)
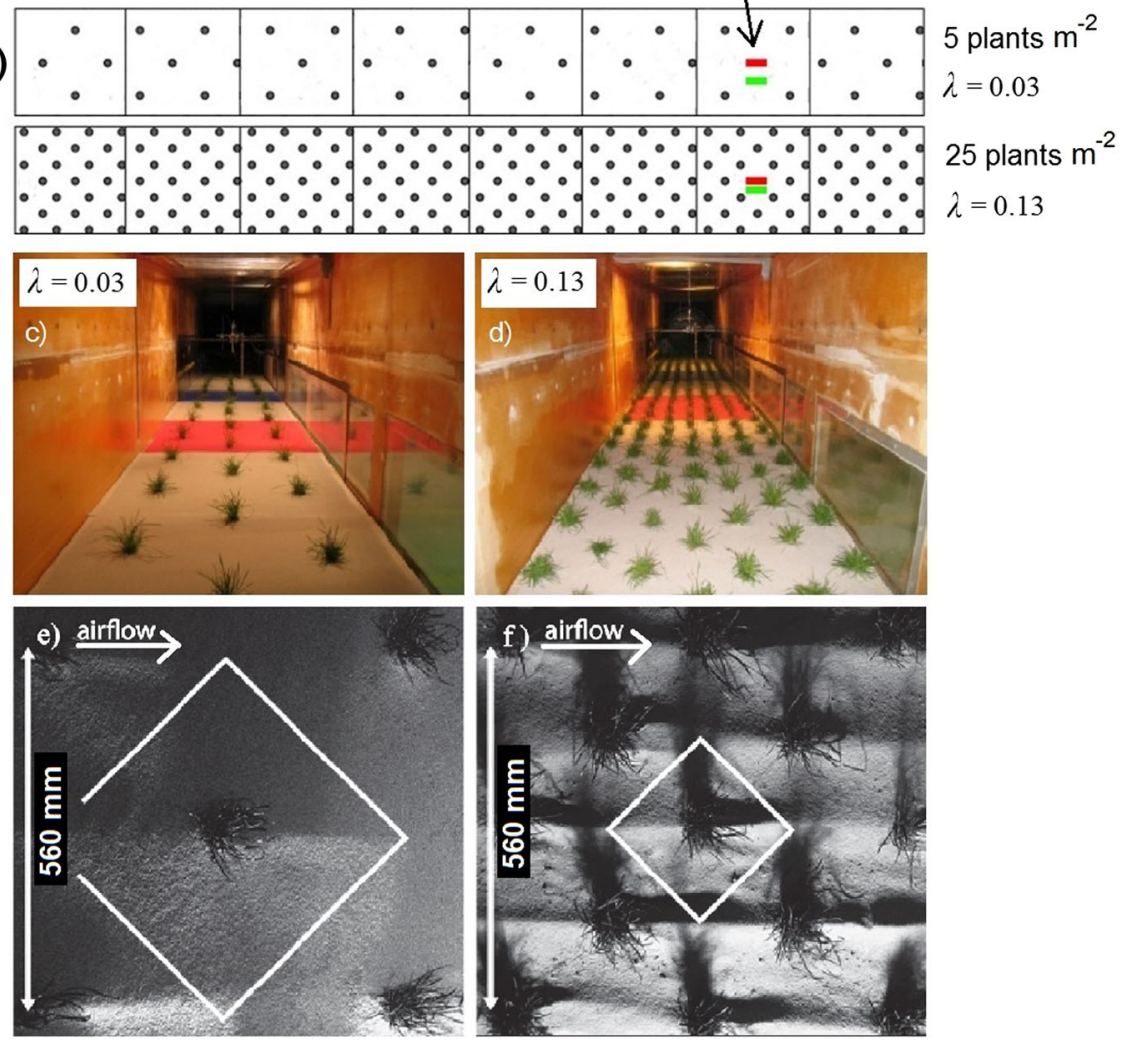

Fig. 1 a Sketch of the wind tunnel showing the spires and artificial roughness elements, the test and the measurement section; b sketch of the three different canopies investigated, a bare surface and two different live plant canopies. The sampler was placed both in line with the plants (red bars) and in between the plant rows (green bars); c, d wind-tunnel images taken from Burri et al. (2012) showing live plant canopies identical to those investigated; $\mathbf{e}, \mathbf{f}$ images taken from Walter et al. (2012b) showing the bed topography after an erosion experiment for the canopies from $\mathbf{c}, \mathbf{d}$

thick sand layer was eroded. The wind-tunnel ceiling was adjusted prior to each experiment with a different canopy density to remove streamwise pressure gradients. Spires and artificial roughness elements were used for preconditioning the boundary-layer flow on the 6-m-long 
section upwind of the plant canopies (Fig. 1). Due to the extensive amount of experimental work involved with the mass-flux measurements, and because only one sediment sampler was available, we did not take measurements in line with the plants and in between the plant rows at every wind speed. For $\lambda=0.03$, the mass-flux measurements were performed in line with the plants for all wind speeds whereas only a few measurements with the sediment sampler between the plant rows were taken for several wind speeds and vice versa for $\lambda=0.13$. The mass flux per box of the sediment sampler is defined as $q(z)=m /(t A)$, where $m$ is the mass per box with an opening area of $A=45 \mathrm{~mm}^{2}$. The measurement time $t$ gives the timespan over which the sediment sampler collected particles at a constant wind speed.

\section{Results and Discussion}

The particle mass-flux measurements are summarized in Table 1 and are generally in good overall agreement with the previous results of Burri et al. (2011) who performed similar measurements in the WSL/SLF wind tunnel. The mass-flux profiles for the three different canopy densities measured in line with the plants at various wind speeds are shown in Fig. 2. For the unsheltered sand surface $(\lambda=0)$, the mass flux generally decreases exponentially with height above the ground (Fig. 2), a result that agrees well with many previous field and wind-tunnel experiments (Rasmussen and Sørensen 2008; Ellis et al. 2009; Gromke et al. 2011; Burri et al. 2011; Rotnicka 2013). The slight kink at a level around the canopy height for $\lambda=0$ is likely the result of the artificial roughness elements used for preconditioning the flow (Fig. 1), which results in the development of an internal boundary layer above the test section (Walter et al. 2012a). These authors measured kinematic
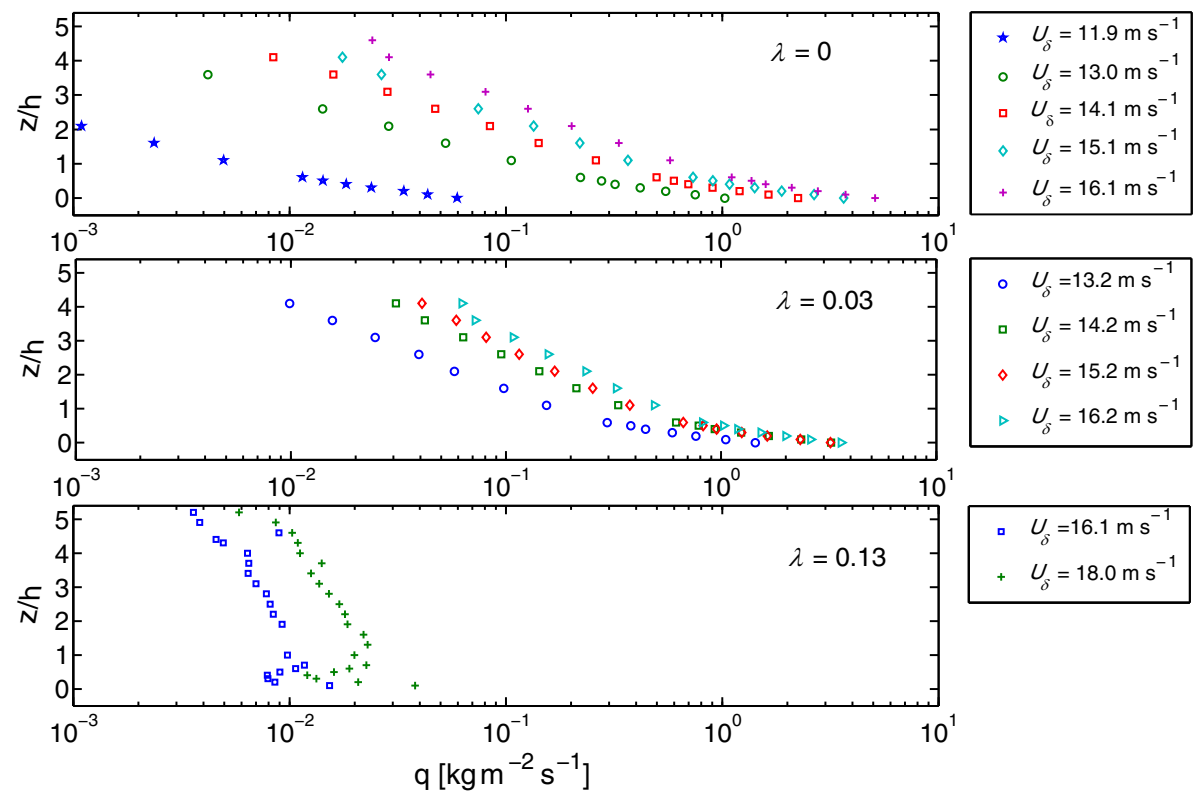

Fig. 2 Particle mass-flux profiles $q(z / h)$ for the three different canopy densities. The profiles were measured within the line of the plants 
Reynolds-stress profiles using two-dimensional (2D) hot-film anemometry with and without artificial roughness elements and found that the elements result in the development of an internal boundary layer with two adjacent constant-stress layers, the lower being at a height of $0.1 \mathrm{~m}(z / h=1)$. The mass-flux profiles for the low canopy density $(\lambda=0.03)$ are similar to those of the bare-sand surface; however, the mass flux in the upper part of the boundary layer $(z / h>2)$ is slightly higher for similar wind speeds compared to the bare-sand surface because of an increase in the boundary-layer thickness due to the presence of the plants. In addition, particles impacting on the plants probably rebound to higher levels above the ground. The kink at $z / h=1$ is slightly more pronounced compared to the baresand surface case, which might be the result of spatial variations of the mass flux within the canopy layer that are not captured with only two sediment sampler measurement positions. The mass-flux profiles significantly changed for the high canopy density case $(\lambda=0.13)$; the mass flux is much reduced and the profiles show less vertical variation compared to the bare-sand surface and the low-density case, which is a result of the sheltering effect of the vegetation on the ground. Due to this sheltering effect, significantly higher wind speeds were necessary to initiate wind erosion (Table 1; Fig. 2). Whereas for the bare-sand surface a measurable mass flux already occurred for a freestream velocity of $U_{\delta}=11.9 \mathrm{~m} \mathrm{~s}^{-1}$, erosion began at $U_{\delta}=16.1 \mathrm{~m} \mathrm{~s}^{-1}$ for the high-density case. Figure 1e, f shows the bed topography after an erosion experiment. The sheltered areas in the lee of the plants where reduced erosion or deposition occurs are clearly visible. The plants increasingly flutter and bend with the flow with increasing wind speed reducing their frontal area by up to $10 \%$ for a freestream velocity of $U_{\delta}=15 \mathrm{~m} \mathrm{~s}^{-1}$, an effect that is also accounted for when calculating the roughness density $\lambda$ (Walter et al. 2012c). Additional information on basic flow properties such as vertical velocity and Reynolds-stress profiles can be found in Walter et al. (2012b) for the plant canopies shown in Fig. 1. However, these measurements were performed in the absence of particle erosion (sediment would likely damage the 2D hot-film anemometer).

From the mass-flux profiles shown in Fig. 2, the total mass flux $Q$ was calculated as $Q=m_{\text {tot }} /(t \cdot l)$ where $m_{\text {tot }}$ is the sum of the sediment masses of all vertical boxes of the sampler and $l=5 \mathrm{~mm}$ is the width of the sampler (Table 1). Because the skin friction velocity $u_{\tau}$ on the ground is responsible for the particle mass-flux magnitude and not the friction velocity $u_{*}$ of the constant-stress layer above the canopy, as is usually used for the determination of particle mass fluxes, $u_{\tau}{ }^{\prime}$ is used instead of $u_{*}$ in the mass-flux equation (Eq. 3), as mentioned earlier. To plot the total mass flux $Q$ as a function of the spatially averaged skin friction velocity $u_{\tau}{ }^{\prime}$, additional information on $u_{\tau}{ }^{\prime}$ for the various canopy measurements is needed. Consequently, we made use of the measured spatially resolved skin friction velocity $u_{\tau}$ of Walter et al. (2012b), obtained for similar live plant canopies as those investigated herein. Up to 32 Irwin sensors (Irwin 1981) were mounted on wooden boards beneath the plant canopies to simultaneously measure the skin friction velocity $u_{\tau}$ for freestream velocities ranging from $2-16 \mathrm{~m} \mathrm{~s}^{-1}$. Irwin sensors are omnidirectional pressure sensors immersed in the wind-tunnel floor where the pressure difference at the sensor can be calibrated against the skin friction velocity $u_{\tau}$ (Walter et al. 2012a, 2014). All $u_{\tau}$ values used herein are based on Irwin sensor measurements from Walter et al. (2012b), and the $u_{\tau}$ measurements are used to obtain $u_{\tau}{ }^{\prime}$ as a function of the freestream velocity $U_{\delta}$ (Fig. 3). For $\lambda=0$,

$$
u_{\tau}^{\prime}=0.0307 U_{\delta}+0.01304
$$

with $R^{2}=0.99$, for $\lambda=0.03$,

$$
u_{\tau}^{\prime}=0.02934 U_{\delta}-0.00209
$$


Table 1 Summary of the mass-flux measurements

\begin{tabular}{llllll}
\hline $\begin{array}{l}\text { Plant density } \\
\left(\mathrm{m}^{-2}\right)\end{array}$ & $\lambda$ & Time $(\mathrm{s})$ & $U_{\delta}\left(\mathrm{m} \mathrm{s}^{-1}\right)$ & $\begin{array}{l}\text { Sampler } \\
\text { position }\end{array}$ & $Q\left(\mathrm{~kg} \mathrm{~m}^{-1} \mathrm{~s}^{-1}\right)$ \\
\hline 0 & 0 & 488 & 11.9 & - & 0.0025 \\
0 & 0 & 217 & 13.0 & - & 0.0490 \\
0 & 0 & 206 & 14.1 & - & 0.1109 \\
0 & 0 & 81 & 15.1 & - & 0.1762 \\
0 & 0 & 57 & 16.1 & - & 0.2609 \\
5.25 & 0.03 & 313 & 12.1 & In & 0.0087 \\
5.25 & 0.03 & 279 & 13.2 & In & 0.0648 \\
5.25 & 0.03 & 70 & 14.2 & In & 0.1446 \\
5.25 & 0.03 & 40 & 14.0 & Between & 0.1079 \\
5.25 & 0.03 & 48 & 15.2 & In & 0.1566 \\
5.25 & 0.03 & 43 & 16.2 & In & 0.1993 \\
5.25 & 0.03 & 33 & 16.3 & Between & 0.2154 \\
24.5 & 0.13 & 549 & 16.1 & In & 0.0042 \\
24.5 & 0.13 & 590 & 16.0 & Between & 0.0026 \\
24.5 & 0.13 & 248 & 17.0 & Between & 0.0055 \\
24.5 & 0.13 & 175 & 18.0 & In & 0.0081 \\
24.5 & 0.13 & 228 & 18.2 & Between & 0.0078 \\
24.5 & 0.13 & 238 & 19.2 & Between & 0.0100 \\
& & & & &
\end{tabular}

In $=$ in line with the plants; between $=$ in between the plant rows

with $R^{2}=0.99$, and for $\lambda=0.13$,

$$
u_{\tau}^{\prime}=0.0003548 U_{\delta}^{2}+0.01157 U_{\delta}+0.02567
$$

with $R^{2}=0.99$.

As shown in Fig. 3, $u_{\tau}{ }^{\prime}$ decreases with increasing roughness density as a result of the sheltering potential of the live plants and the shear-stress partitioning effect (Raupach 1992). The total mass flux $Q$ as a function of the spatially averaged skin friction velocity $u_{\tau}{ }^{\prime}$ for the three different canopy densities is shown in Fig. 4. Each of the total mass fluxes $Q$ is an average of two sediment sampler positions, one with the sampler placed in between the plant rows in the streamwise direction and one where it was placed in line with the plants. As we did not measure at both positions for every wind speed, the missing measurements (Table 1) were inferred by assuming that the ratio of the mass flux between the two positions is the same for different wind speeds. The difference in mass flux between the two sediment sampler positions was typically smaller than the difference between two consecutive wind speeds. It needs to be mentioned that the measurements at only two sampler positions merely result in an estimate of the spatially averaged mass flux within the canopy layer. By fitting Eq. 3 to the mass-flux data, with $b$ and $u_{\tau t}{ }^{\prime}$ being independent fit parameters, the following results are obtained. For $\lambda=0$,

$$
Q=24.1\left(u_{\tau}{ }^{\prime}-0.29\right)^{3}
$$

with $R^{2}=0.99$, for $\lambda=0.03$,

$$
Q=12.2\left(u_{\tau}{ }^{\prime}-0.21\right)^{3}
$$




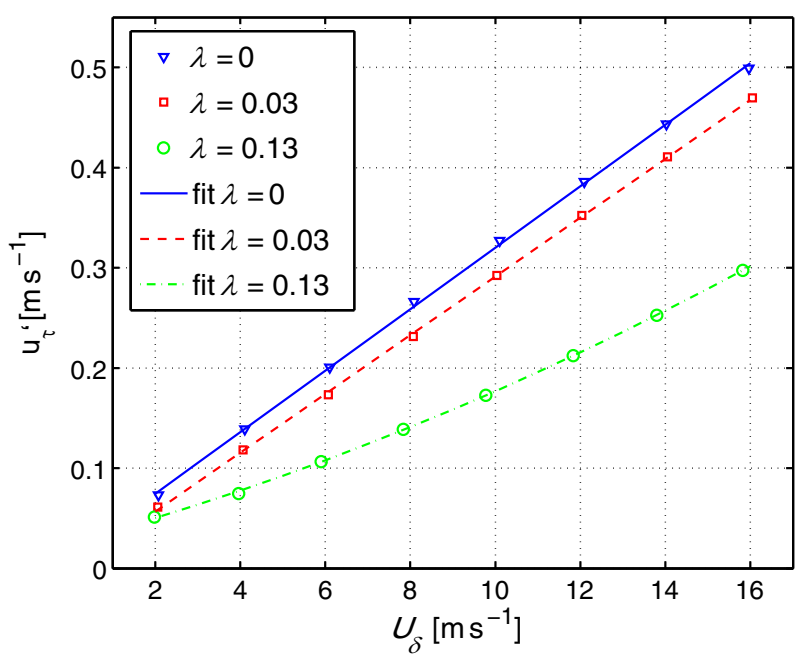

Fig. 3 Spatially-averaged skin friction velocity $u_{\tau}{ }^{\prime}$ as a function of freestream velocity $U_{\delta}$ for the three live plant-canopy densities. The data are from Walter et al. (2012b) (same data as in Fig. 5)

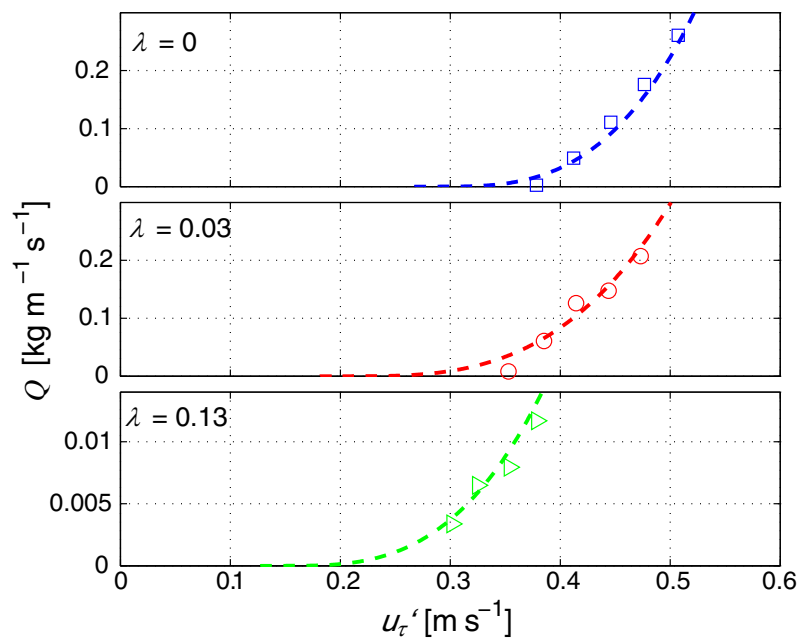

Fig. 4 Total particle mass flux $Q$ as a function of the spatially averaged skin friction velocity $u_{\tau}{ }^{\prime}$ for the three different canopy densities

with $R^{2}=0.94$, and for $\lambda=0.13$

$$
Q=1.10\left(u_{\tau}^{\prime}-0.15\right)^{3}
$$

with $R^{2}=0.95$.

For the unsheltered case $(\lambda=0)$, the particle entrainment threshold is $u_{\tau t^{\prime}}=0.29 \mathrm{~m} \mathrm{~s}^{-1}$ (Eq. 5a), a result that agrees well with previous measurements for the same sediment; see Burri et al. (2011) and Walter et al. (2012b). The threshold for the onset of particle erosion decreases gradually to $u_{\tau t}{ }^{\prime}=0.21 \mathrm{~m} \mathrm{~s}^{-1}$ for the low-density case and to $u_{\tau t^{\prime}}=0.15 \mathrm{~m} \mathrm{~s}^{-1}$ for the high-density case. This decrease is physically plausible by considering the increasing 


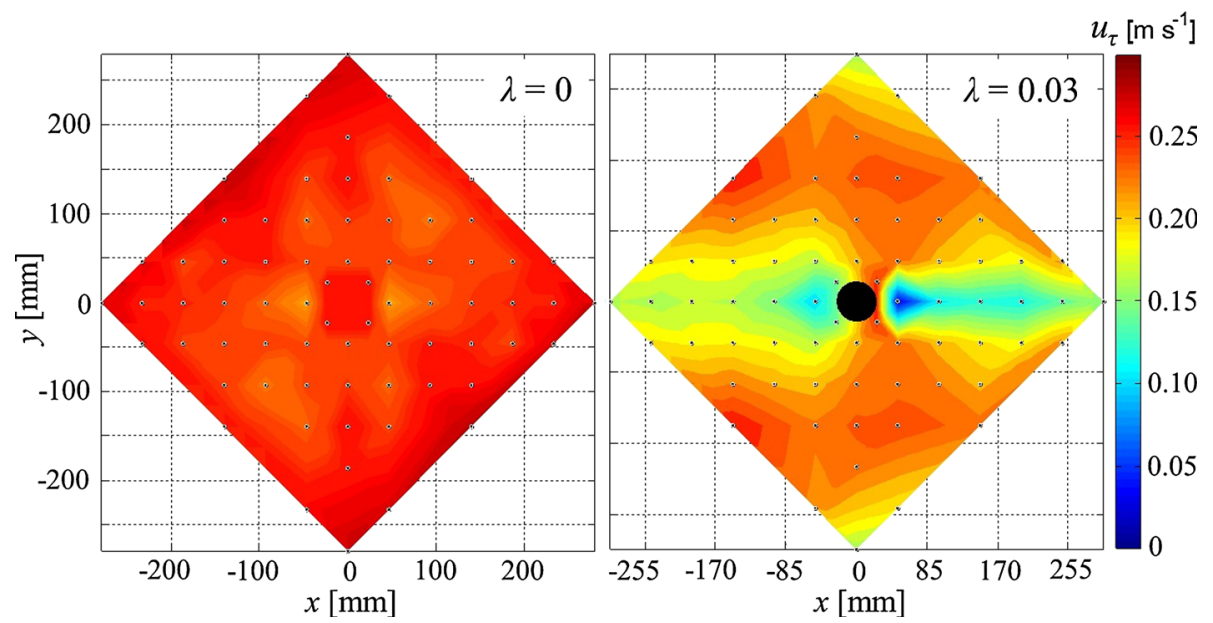

Fig. 5 Skin-friction-velocity distribution for bare surface $(\lambda=0$, left $)$ and low canopy density case $(\lambda=0.03$, right) for a freestream velocity of $U_{\delta}=12 \mathrm{~m} \mathrm{~s}^{-1}$. The distribution on the right shows the typical flow speedup zones with peak skin friction velocities on both sides of the plant (black dot) and a flow stagnation zone and shelter area upwind and downwind of the plant. The airflow was from left to right. The data were taken from Walter et al. (2012b) (same data as in Fig. 3)

spatial variability of the skin friction velocity when increasing the roughness density. For a surface sheltered by plants with a lower spatially averaged $u_{\tau}{ }^{\prime}$ relative to a bare-sand surface, the spatial variations in $u_{\tau}$ result in local peak $u_{\tau}{ }^{\prime \prime}$ values that might be as high as the threshold value of $u_{\tau t^{\prime}}=0.29 \mathrm{~m} \mathrm{~s}^{-1}$ for the bare surface. Such spatial variations in $u_{\tau}$ are shown in Fig. 5 for two roughness densities $(\lambda=0$ and $\lambda=0.03)$ that are also based on the Irwin sensor measurements of Walter et al. (2012b). Whereas for the bare surface $u_{\tau}$ is homogenously distributed with an average value close to the threshold of $u_{\tau t^{\prime}}=0.29 \mathrm{~m} \mathrm{~s}^{-1}$, the low canopy density case shows $u_{\tau}$ values close to the threshold only in the zones to both sides of the plants. In these areas, speed-up of the flow occurs and particle entrainment may already be initiated for spatially averaged $u_{\tau}{ }^{\prime}$ values lower than the spatially-averaged threshold value $u_{\tau t^{\prime}}=0.29 \mathrm{~m} \mathrm{~s}^{-1}$ for the bare surface. These spatial variations in $u_{\tau}$ explain the decrease of the threshold $u_{\tau t}{ }^{\prime}$ from 0.29 to $0.15 \mathrm{~m} \mathrm{~s}^{-1}$ with increasing roughness density $\lambda$ (Eq. 5).

The dependence of the threshold value $u_{\tau t}{ }^{\prime}$ on the roughness density $\lambda$ as given by the values in Eq. 5 is shown in Fig. 6. The mass-flux equation (Eq. 3) can also be linked to the local peak skin friction velocity $u_{\tau}{ }^{\prime \prime}$ or the freestream velocity $U_{\delta}$ instead of the spatially-averaged skin friction velocity $u_{\tau}{ }^{\prime}$. However, since the spatially-averaged skin friction velocity $u_{\tau}{ }^{\prime}$ determines the magnitude of particle entrainment it provides the best estimate of the erosive potential and of the mass flux, whereas the local peak of the skin friction velocity $u_{\tau}{ }^{\prime \prime}$ is more responsible for the onset of erosion. The following relation provides a first simple approach for describing $u_{\tau t}^{\prime}(\lambda)$ based on the results from Eq. 5

$$
\begin{aligned}
u_{\tau t}^{\prime}(\lambda) & =\left(u_{\tau t}^{\prime}(\lambda=0)-\frac{u_{\tau t}^{\prime}(\lambda=0)}{a^{r}}\right) \exp \left(-\frac{\lambda}{k}\right)+\frac{u_{\tau t}^{\prime}(\lambda=0)}{a^{r}} \\
& =0.14 \exp \left(-\frac{\lambda}{0.0348}\right)+0.15
\end{aligned}
$$


Fig. 6 Dependence of skin-friction-velocity threshold $u_{\tau t}{ }^{\prime}$ on roughness density $\lambda$. The surface is expected to be entirely sheltered for $\lambda>0.25$, as found, e.g., by Walter et al. (2012c)

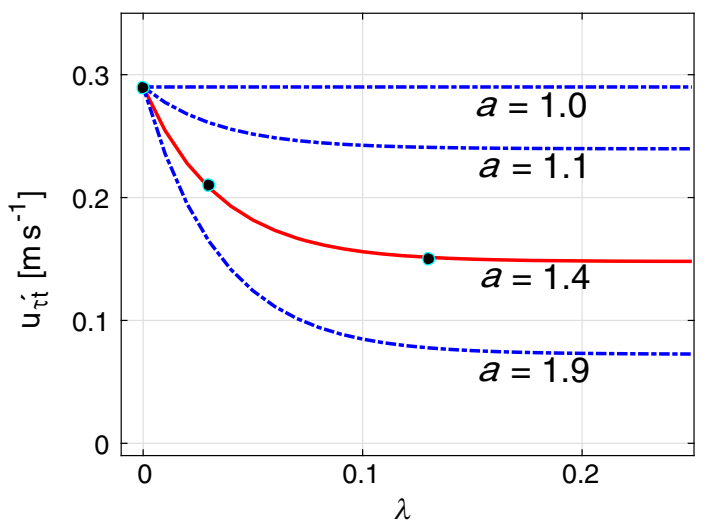

where $r$ and $k$ are independent fit parameters. Because the mass-flux equation (Eq. 3 ) is based on the spatially-averaged skin friction velocity $u_{\tau}{ }^{\prime}$, but the local peak $u_{\tau}{ }^{\prime \prime}$ is responsible for the initiation of sediment entrainment, the peak mean-stress ratio $a=\tau^{\prime \prime} / \tau^{\prime}$, as defined in Walter et al. (2012c), and where $\tau=\left(\rho u_{\tau}\right)^{2}$, is used in Eq. 6 as a parameter describing the reduction of $u_{\tau t}{ }^{\prime}$ with increasing roughness density $\lambda$. Walter et al. (2012c) measured surface shear stress on the ground beneath live plant canopies using Irwin sensors (see Figs. 3, 5) and found a strong linear relation with slope $a$ between the peak $\tau^{\prime \prime}$ and the spatially averaged $\tau$ ' surface shear stress, resulting in $u_{\tau}{ }^{\prime \prime}=a^{1 / 2} u_{\tau}{ }^{\prime}$. A slope of $a=1.4$ was found for the plant canopies and $a=1.9$ for wooden block arrays; furthermore, $a$ was found to be independent of the roughness density $\lambda$ for the plant canopies.

The origin of Eq. 6 is based on the following three arguments or boundary conditions: (i) for $\lambda=0$, the threshold must equal the threshold for the specific bare sediment surface; (ii) for $\lambda>0, u_{\tau t}{ }^{\prime}$ must decrease with increasing $\lambda$ because the spatial variations induced by the non-erodible roughness elements result in a local peak $u_{\tau}{ }^{\prime \prime}>u_{\tau}{ }^{\prime}$ responsible for the initiation of sediment erosion on the sheltered surface (Fig. 5). Whether or not such a decrease is as smooth as shown in Fig. 6 for $0<\lambda<0.05$ or more abrupt could be verified by future erosion experiments or numerical simulations; (iii) $u_{\tau}{ }^{\prime}$ must be constant over a wide range of higher canopy densities $(\lambda>0.05)$ because the peak mean-stress ratio $a$ was found to be constant for a wide range of $\lambda$ (Walter et al. 2012c). Because the difference between the peak and the mean skin friction velocity $u_{\tau}$ is responsible for the lower threshold values for $\lambda>0$, a term is introduced into Eq. 6 where the bare surface threshold $u_{\tau t}{ }^{\prime}(\lambda=0)$ is divided by $a^{r}$. The exponent $r=2$ was found to result in the best fit to the data in Fig. 6 . An exponent of $r>1 / 2$ other than in $u_{\tau}^{\prime \prime}=a^{1 / 2} u_{\tau}{ }^{\prime}$ may be explained by the fact that the initiation of sediment erosion not only depends on temporally averaged peak and mean skin friction velocities but also on their variation in time. Because Eq. 6 contains two fit parameters $r$ and $k$, and only two independent data points are available beside $u_{\tau t}{ }^{\prime}(\lambda=0)=0.29 \mathrm{~m} \mathrm{~s}^{-1}$, a perfect fit to the data is obtained (Fig. 6). The additional lines for $a=1.0,1.1$, and 1.9 in Fig. 6, where $a=1.9$ is the value found for the wooden blocks used in Walter et al. (2012c), are included to illustrate the variation of $u_{\tau t}{ }^{\prime}(\lambda)$ for different values of $a$ assuming $r=2$ is a constant. As expected, the threshold values $u_{\tau t}{ }^{\prime}(\lambda)$ decrease for the wooden blocks with $a=1.9$ relative to the live plant values. Because the blocks result in a stronger deflection of the flow (Walter et al. 2012c) resulting in a high peak $u_{\tau}{ }^{\prime \prime}$ in the speed-up zones relative to the spatial average $u_{\tau}{ }^{\prime}$, the threshold $u_{\tau t}{ }^{\prime}$ is reduced. 
Fig. 7 Dependence of parameter $b$ on roughness density $\lambda$. The coefficient of determination is $R^{2}=0.99$

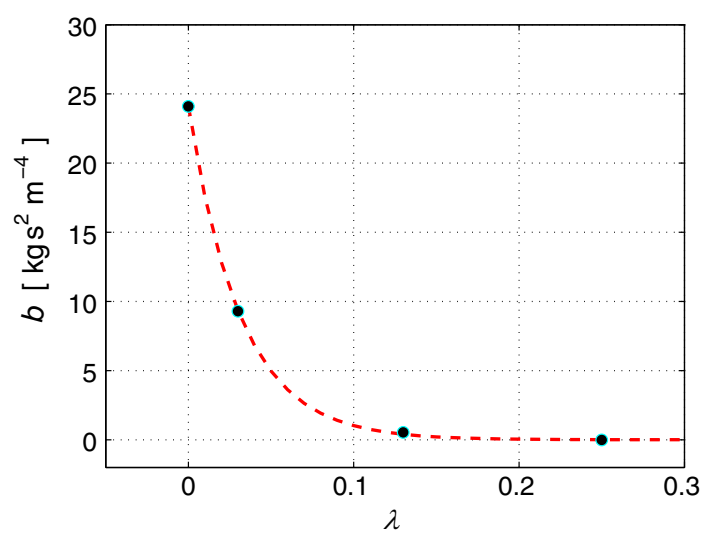

The dependence of the fit parameter $b$ (Eq. 3) on the roughness density $\lambda$ is shown in Fig. 7. An additional data point is included in Fig. 7, which is motivated by a high canopy density with $\lambda=0.25$ where the sediment surface is expected to be entirely sheltered and the particle mass flux must be zero, and thus, $b=0$ (Raupach 1992; Walter et al. 2012c). The perfect exponential decrease of the parameter $b$ reflects previously measured exponential decreases of the total mass flux with increasing canopy density (Eq. 2) (e.g. Burri et al. 2011). For our measurements, we obtain the following relation

$$
b(\lambda)=24.1 \exp (-22.9 \lambda)
$$

where the $b(\lambda)$ dependence and thus the curve in Fig. 7 (Eq. 7) are only valid for the sediment used in this study, implying sediments with a different particle-size distribution require the determination of the parameters in Eq. 7 for each specific case.

It needs to be recalled that we aim to provide a first approach towards a simple framework based on widely used relations allowing the estimation of particle mass fluxes on sheltered surfaces using a minimum number of input parameters. Unfortunately, the limited data available inhibit a more detailed analysis. The most prominent difficulties involved with our measurements include: (i) the mass flux was measured at only two positions within the canopy to obtain a spatially averaged value. (ii) Accurate mass-flux measurements close to the threshold, where only a few particles are trapped, are quite difficult to perform in a three-dimensional flow with live plants; therefore, only measurements with a significant, measureable amount of trapped particles were evaluated. (iii) The experiments were conducted with a quasi-infinite supply of loose sediment at the surface that, in general, does not reflect natural conditions.

Furthermore, the live plant canopies used for the experiments differ in important ways from real natural vegetation canopies. Natural vegetation canopies typically consist of various plant species with different sizes that are irregularly distributed on the ground. However, the fact that our plants are of similar size, trimmed to a standard height, and arranged with regular spacing allowed us to systematically investigate the influence of the canopy density on the particle mass flux. However, these live plants and those used by Burri et al. (2011) imitate natural plant canopies much more realistically than canopies of rigid and non-porous roughness elements used in many previous wind-tunnel investigations. Generally, our results are expected to be similar for other plant species with comparable morphology and size. The regular spacing of the plants in the wind tunnel may even be beneficial, considering 
that seeding machines typically used in revegetation projects and farming arrange plants in regular arrays.

\section{Final Relation}

Combining Eqs. 6 and 7 with Eq. 3 results in the following relation that can be used to estimate particle mass fluxes for surfaces sheltered by live vegetation,

$$
Q\left(\lambda, u_{\tau}{ }^{\prime}\right)=24.1 \exp (-22.9 \lambda)\left(u_{\tau}{ }^{\prime}-\left(0.14 \exp \left(-\frac{\lambda}{0.0348}\right)+0.15\right)\right)^{3},
$$

valid only for the sediment $(d=0.4-0.8 \mathrm{~mm})$ and live plants of similar morphology and size to those used in this study. If different sediments are of interest, an appropriate baresand surface threshold $u_{\tau t}{ }^{\prime}(\lambda=0)$ must be used in Eq. 6, and also Eq. 7 must be adapted to the specific particle-size distribution; both require additional experiments or simulations. Different non-erodible roughness elements require an adaption of the value for the peak mean-stress ratio $a$ in Eq. 6. A sensitivity study has shown that changing $a$ from 1.4 (plants) to 1.9 (blocks) results in mass fluxes up to 5-10 times that of the plant case for low $u_{\tau}{ }^{\prime}$ close to the threshold. For higher $u_{\tau}{ }^{\prime}$, the mass fluxes are only 1.5 times higher than for the plant case. In Eq. 8, the roughness density $\lambda=A_{\mathrm{f}} / S$ can be calculated from the geometry of the canopy of interest. The spatially-averaged skin friction velocity $u_{\tau}{ }^{\prime}$ either can be taken from numerical simulations or measurements, or can be derived from friction velocity $\left(u_{*}\right)$ or wind-speed $\left(U_{\delta}\right)$ measurements or simulations using the model of Raupach (1992). With Eq. 8, the mass flux for a wide range of roughness densities and skin friction velocities can be estimated.

\section{Summary and Outlook}

Sediment mass-flux measurements performed in a controlled wind-tunnel environment over live plant canopies of different densities are used to determine a simple relation between the total mass flux $Q$ and the skin friction velocity $u_{\tau}{ }^{\prime}$ and the canopy density $\lambda$. The only parameters that are needed are: (1) the bare-surface threshold skin friction velocity $u_{\tau t}{ }^{\prime}(\lambda=$ 0 ) that depends on the particle-size distribution and density of the sediment (Eq. 6); (2) the parameter $a$ defining the linear relation between the peak and the average surface shear stress (Eq. 6); (3) the roughness density $\lambda$ for the plants or the non-erodible elements; and (4) the spatially averaged skin friction velocity $u_{\tau}{ }^{\prime}$ that either can be taken from measurements and numerical simulations, or can be estimated from a given freestream velocity $U_{\delta}$ using the model of Raupach (1992). Our results show that an estimate of particle mass fluxes on surfaces sheltered by non-erodible roughness elements can be obtained by making use of only a few input parameters. Because this study is merely a first approach introducing a new framework based on well-accepted relations for estimating particle mass fluxes, further detailed studies are necessary to improve and refine the relations. Such studies might include more detailed mass-flux measurements performed with sediments of different size distributions, preferably closer to the particle erosion threshold and with a higher spatial resolution.

Acknowledgements We would like to thank the Swiss National Science Foundation (SNF) for financing this project. We are also grateful to Matthew von Pokorny, Christof Gromke, Katrin Burri, and Frank Graf for their 
help with the experimental set-up and the measurement technique. The data presented herein are available on request.

\section{References}

Bagnold R (1941) The physics of blown sand and desert dunes. Methuen, London, 265 pp

Bitton M, Hesp PA (2013) Vegetation dynamics on eroding to accreting beach-foredune systems, Florida panhandle. Earth Surf Process Landf 38(12):1472-1480

Burri K, Gromke C, Lehning M, Graf F (2011) Aeolian sediment transport over vegetation canopies: a wind tunnel study with live plants. Aeolian Res 3:205-213

Burri K, Gromke C, Leonard KC, Graf F (2012) Spatial patterns of aeolian sediment deposition in vegetation canopies: observations from wind tunnel experiments using colored sand. Aeolian Res 8:65-73

Crawley DM, Nickling WG (2003) Drag partition for regularly-arrayed rough surfaces. Boundary-Layer Meteorol 107:445-468

Diebold M, Higgins C, Fang J, Bechmann A, Parlange M (2013) Flow over hills: a large-eddy simulation of the bolund case. Boundary-Layer Meteorol 148(1):177-194

Dong Z, Sun H, Zhao A (2004) WITSEG sampler: a segmented sand sampler for wind tunnel test. Geomorphology 59:119-129

Ellis JT, Li B, Farrell EJ, Sherman DJ (2009) Protocols for characterizing aeoli an mass-flux profiles. Aeolian Res 1(1-2):19-26. doi:10.1016/j.aeolia.2009.02.001

Gillette DA, Stockton PH (1989) The effect of nonerodible particles on wind erosion of erodible surfaces. J Geophys Res 94:12885-12893

Gromke C, Manes C, Walter B, Lehning M, Guala M (2011) Aerodynamic roughness length of fresh snow. Boundary-Layer Meteorol 141:21-43. doi:10.1007/s10546-011-9623-3

Groot-Zwaaftink CD, Mott R, Lehning M (2013) Seasonal simulation of drifting snow sublimation in Alpine terrain. Water Resour Res 49(3):1581-1590

Groot Zwaaftink CD, Diebold M, Horender S, Overney J, Lieberherr G, Parlange MB, Lehning M (2014) Modelling small-scale drifting snow with a Lagrangian stochastic model based on large-eddy simulations. Boundary-Layer Meteorol 153:117-139. doi:10.1007/s10546-014-9934-2

Hesp PA (1981) The formation of shadow dunes. Sediment Petrol 51:101-111

Hesse PP, Simpson RL (2006) Variable vegetation cover and episodic sand movement on longitudinal desert sand dunes. Geomorphology 81:276-291

Irwin HPAH (1981) Asimple omnidirectional sensor for wind-tunnel studies of pedestrian-level winds. J Wind Eng Ind Aerodyn 7:219-239

Kok JF, Parteli EJR, Michaels TI, Karam DB (2012) The physics of wind-blown sand and dust. Rep Prog Phys 75:106901. doi:10.1088/0034-4885/75/10/106901

Li J, Okin GS, Alvarez L, Epstein H (2007) Quantitative effects of vegetation cover on wind erosion and soil nutrient loss in a desert grassland of southern New Mexico, USA. Biogeochemistry 85:317-332

Li J, Okin GS, Herrick JE, Belnap J, Munson SM, Miller ME, Vest KR, Draut AE (2013) Evaluation of a new model of Aeolian transport in the presence of vegetation. J Geophys Res Earth Surf 118:288-306. doi:10.1002/jgrf.20040

McKenna Neuman C (2003) Effects of temperature and humidity upon the entrainment of sedimentary particles by wind. Boundary-Layer Meteorol 108:61-89

Nemoto M, Nishimura K (2004) Numerical simulation of snowsaltation and suspension in a turbulent boundary layer. J Geophys Res 109:D18206

Nishimura K, Hunt JCR (2000) Saltation and incipient suspension above a flat particle bed below a turbulent boundary layer. J Fluid Mech 417:77-102

Okin GS (2008) A new model of wind erosion in the presence of vegetation. J Geophys Res 113:F02S10. doi:10.1029/2007JF000758

Pomeroy JW, Gray DM (1990) Saltation of snow. Water Resour Res 26(7):1583-1594. doi:10.1029/ WR026i007p01583

Rasmussen KR, Sørensen M (2008) Vertical variation of particle speed and flux density in aeolian saltation: measurement and modeling. J Geophys Res 113:F02S12. doi:10.1029/2007JF000774

Raupach MR (1992) Drag and drag partition on rough surfaces. Boundary-Layer Meteorol 60:375-395

Rotnicka J (2013) Aeolian vertical mass-flux profiles above dry and moist sandy beach surfaces. Geomorphology 187:27-37

Shao Y, Li A (1999) Numerical modelling of saltation in the atmospheric surface layer. Boundary-Layer Meteorol 91:199-225 
Shao Y, Raupach MR (1993) Effect of saltation bombardment on the entrainment of dust by wind. J Geophys Res 98(D7):12,719-12,726

Thornton PE, Zimmermann NE (2007) An improved canopy integration scheme for a land surface model with prognostic canopy structure. J Clim 20:3902-3923

Vinkovic I, Aguirre C, Ayrault M, Simoëns S (2006) Large-eddy simulation of the dispersion of solid particles in a turbulent boundary layer. Boundary-Layer Meteorol 121(2):283-311

Walter B, Gromke C, Leonard K, Clifton A, Lehning M (2012) Spatially resolved skin friction velocity measurements using Irwin sensors: a calibration and accuracy analysis. J Wind Eng Ind Aerodyn 144:104106. doi:10.1016/j.jweia.2012.02.018

Walter B, Gromke C, Leonard K, Manes C, Lehning M (2012b) Spatio-temporal surface shear stress variability in live plant canopies and cube arrays. Boundary-Layer Meteorol 143(2):337-356. doi:10.1007/s10546011-9690-5

Walter B, Gromke C, Lehning M (2012c) Shear stress partitioning in live plant canopies and modifications to Raupach's model. Boundary-Layer Meteorol 144(2):217-241. doi:10.1007/s10546-012-9719-4

Walter B, Horender S, Voegeli C, Lehning M (2014) Experimental assessment of Owen's second hypothesis on surface shear stress induced by a fluid during sediment saltation. Geophys Res Lett 41:6298-6305

Weil JC, Sullivan PP, Moeng CH (2004) The use of large-eddy simulations in Lagrangian particle dispersion models. J Atmos Sci 61:2877-2887 